\title{
GOVERNANÇA AMBIENTAL GLOBAL COMO CRITÉRIO REGULADOR E GARANTIDOR DA JUSTIÇA AMBIENTAL
}

\section{GLOBAL ENVIRONMENTAL GOVERNANCE AS A REGULATORY AND GUARANTEE CRITERION FOR ENVIRONMENTAL JUSTICE}

\author{
Denise Schmitt Siqueira Garcia ${ }^{1}$ \\ Heloise Siqueira Garcia ${ }^{2}$
}

\section{RESUMO}

Este artigo trabalha com a temática da Governança Ambiental Global para o alcance da Justiça Ambiental, apresentando como objetivo geral analisar a importância da primeira em suas esferas pública, empresarial e da sociedade civil para a regulamentação e garantia da segunda. Constatando-se, ao final, que a Justiça Ambiental, na qualidade de problema comum humanitário, apresenta-se como o objetivo principal da Governança Ambiental Global. Na metodologia foi adotado o método indutivo, tendo sido acionadas as técnicas do referente, da categoria, dos conceitos operacionais, da pesquisa bibliográfica e do fichamento.

Palavras-Chave: Governança Ambiental; Governança Global; Justiça Ambiental.

\section{ABSTRACT}

This article deals with the theme of Global Environmental Governance to the achievement of Environmental Justice, presenting as general objective to analyze the importance of the first in its public, business and civil society spheres for the regulation and guarantee of the second. Noting up at the end that the Environmental Justice, as a common humanitarian problem, presents itself as the main objective of Global Environmental Governance. In the methodology was adopted the inductive method, having been applied the techniques of the referent, category, operational concepts, bibliographical research and file.

Keywords: Environmental Governance; Global Governance; Environmental Justice.

\footnotetext{
${ }^{1}$ Doutora pela Universidade de Alicante na Espanha. Professora do Programa de Pós-Graduação Stricto Sensu em Ciência Jurídica da UNIVALI - PPCJ. Mestre em Direito Ambiental pela Universidade de Alicante - Espanha. Mestre em Ciência Jurídica. Especialista em Direito Processual Civil. Professora no Programa de Pós-Graduação Stricto Sensu em Ciência Jurídica, nos cursos de Doutorado e Mestrado em Ciência Jurídica, e na Graduação no Curso de Direito da Universidade do Vale do Itajaí UNIVALI. Membro do grupo de pesquisa "Estado, Direito Ambiental, Transnacionalidade". Pesquisadora do projeto de pesquisa aprovado no $\mathrm{CNPq}$ intitulado: "Análise comparada dos limites e das possibilidades da avaliação ambiental estratégica e sua efetivação com vistas a contribuir para uma melhor gestão ambiental da atividade portuária no Brasil e na Espanha”. Advogada. E-mail: denisegarcia@univali.br

${ }^{2}$ Doutoranda do Programa de Pós Graduação Stricto Sensu em Ciência Jurídica - PPCJ - UNIVALI. Pesquisadora dos Grupos de pesquisa vinculados ao CNPq "Direito Prospectivo e Sustentabilidade" e "Direito Ambiental, Transnacionalidade e Sustentabilidade". Mestre em Ciência Jurídica pelo PPCJ - UNIVALI. Mestre em Derecho Ambiental y de la Sostenibilidad pela Universidad de Alicante - Espanha. Pós graduanda em Direito Previdenciário e do Trabalho pela UNIVALI. Graduada em Direito pela Universidade do Vale do Itajaí - UNIVALI. Advogada. Email: helo_sg@ hotmail.com
} 


\section{INTRODUÇÃO}

O presente artigo tem o condão de trazer ao debate dois temas de suma importância que são a Governança e a Justiça Ambiental. A Governança, dentro desse contexto deve ser vista como um processo de interação entre os atores sociais e institucionais para o alcance de uma efetiva gestão social/ambiental. Essa efetiva gestão social/ambiental, portanto, fará com que se consiga alcançar a Justiça Ambiental que é o outro tema central da presente pesquisa.

Desta forma, o objetivo geral é analisar a importância da Governança Ambiental Global, considerada na esfera pública, empresarial e da sociedade civil, para a regulamentação e garantia da Justiça Ambiental, considerando esta como sendo uma ideia de justiça na distribuição do ambiente entre as pessoas. E como objetivos específicos compreender a Governança Global, a partir do surgimento da sua construção teórica e da diferenciação conceitual com o governo e a governabilidade; e estudar a Justiça Ambiental histórico e conceitualmente, mas principalmente com vistas a compreendê-la a partir das perspectivas da Governança Ambiental Global.

Esclarece-se, ainda, que o problema de pesquisa para este artigo pode ser sintetizado na seguinte indagação: O que é Governança global e qual sua importância para o alcance da Justiça Ambiental?

Para tanto o artigo foi dividido em três partes: Noções de Governança global; Distinção de nomenclaturas: governo e Governança; A Justiça Ambiental e a Governança Ambiental Global.

Com relação à metodologia adotada ressalta-se que a opção das autoras deu-se pelo método indutivo, tendo sido acionadas as técnicas do referente ${ }^{3}$, da categoria ${ }^{4}$, dos conceitos operacionais $^{5}$, da pesquisa bibliográfica ${ }^{6}$ e do fichamento ${ }^{7}$.

\footnotetext{
3 "explicitação prévia do motivo, objetivo e produto desejado, delimitado o alcance temático e de abordagem para uma atividade intelectual, especialmente para uma pesquisa". (PASOLD, 2007, p. 241).

4 "palavra ou expressão estratégica à elaboração e/ou expressão de uma idéia". (PASOLD, 2007, p. 229).

5 "definição estabelecida ou proposta para uma palavra ou expressão, com o propósito de que tal definição seja aceita para os efeitos das idéias expostas". (PASOLD, 2007, p. 229).

6 "Técnica de investigação em livros, repertórios jurisprudenciais e coletâneas legais". (PASOLD, 2007, p. 240).

7 "Técnica que tem como principal utilidade otimizar a leitura na Pesquisa Científica, mediante a reunião de elementos selecionados pelo Pesquisador que registra e/ou resume e/ou reflete e/ou analisa de maneira sucinta, uma Obra, um Ensaio, uma Tese ou Dissertação, um Artigo ou uma aula, segundo Referente previamente estabelecido". (PASOLD, 2007, p. 233).
} 


\section{NOÇÕES DE GOVERNANÇA GLOBAL}

As primeiras manifestações de Governança ambiental foram estimuladas pelo esgotamento dos recursos naturais, como a escassez de madeira para construção de moradias, fortificações, móveis, instrumentos e combustível, cuja exploração havia se tornado intensa desde a era medieval. (BARBIERI, 2011, p. 20).

Assim, a nível global, várias foram as ocorrências de danos ambientais que chamaram a atenção da comunidade internacional para necessidade de uma maior reflexão quanto à necessidade da proteção do Meio Ambiente.

Relacionam-se essas ocorrências de forma exemplificativa:

1. 10.6.1976. Seveso, Itália. Acidente industrial provocado por empresa Suíça. Tanques de armazenagem romperam, liberando TCDD $(2,3,7,8$ tetraclorodibenzo - p - dioxina). Esse desastre levou a União Européia a publicar a Diretiva de Seveso, que estabeleceu regulamentos rígidos, tendo sido atualizada em 1999 e complementada em 2005;

2. 1978. Acidente com o satélite artificial soviético de telecomunicações Cosmos 924, que caiu em território canadense, despejando material radioativo;

3. 16.3.1978. O superpetroleiro Amoco Cádiz, vindo do golfo Pérsico a Roterdã, com 227.000 toneladas de óleo cru, partiu-se ao meio na costa bretã, França, em uma tempestade, criando uma maré que destruiu praias e vida marinha, com enormes prejuízos à pesca e ao turismo;

4. 1984. Acidente na cidade de Bhopal, na Índia, envolvendo uma fábrica de pesticidas, cuja atividade negligente causou um vazamento de gás tóxico que envenenou toda a população, matando mais de 2.000 pssoas e deixando 2000.000 cegas ou feridas;

5. 1986. Acidente nuclear de Chernobyl, na Ucrânia, URSS, cuja explosão liberou uma nuvem de material radioativo que foi levada pelo vento aos países vizinhos;

6. 1986. Incêndio ocorrido na empresa química Sandoz, na Suíça. O rio Reno foi gravemente contaminado por produtos químicos agrícolas, solventes e mércurio, matando a fauna aquática e ameaçando o abastecimento de água potável na Alemanha e da Holanda;

7. entre 1984 e 1987, 60 milhões de pessoas, na maioria crianças, morreram de doenças intestinais decorrentes de desnutrição e da ingestão de água imprópria para o consumo.

8. entre 1984 e 1987, a crise africana ligada ao meio ambiente e ao desenvolvimento, desencadeada pela seca, pôs em risco de vida de 35 milhões de pessoas, matando cerca de um milhão. (GRANZIERA, 2009, p. 37-39).

Não restam dúvidas acerca da necessidade de uma Governança que seja global e efetiva, existindo esse consenso desde o início do século XXI, quando em reuniões, documentos e 
declarações de organismos como a ONU, G8 $8^{8}$ e $\mathrm{G} 20^{9}$, aparecem em vários momentos a expressão Governança global como sendo essencial nos processos de desenvolvimento econômico e social, integração e solução de problemas comuns. (GONÇALVES; COSTA, 2011, p.15).

"Problemas ambientais exigem respostas globais. As iniciativas para enfrentá-los propiciam ao longo do tempo o surgimento de diversos acordos multilaterais, bem como órgãos intergovernamentais, para administrá-los, e mecanismos de ação internacional”. (BARBIERI, 2011, p. 27).

Diversos congressos científicos internacionais antecederam as iniciativas de gestão ambiental de caráter global. A ideia de realizar um encontro internacional sobre proteção da natureza segue paralelamente à criação de parques nacionais nos Estados Unidos, iniciada pelo Parque de Yellowstone, em 1872. O primeiro acordo internacional foi assinado em Paris, em 1883, e seu objetivo era proteger as focas do mar de Behring. Esta cidade também foi sede da Convenção para Proteção dos Pássaros Úteis à Agricultura realizada em 1895 e do Congresso Internacional para proteção da paisagem. O I Congresso Internacional para proteção da natureza, realizado em Paris, em 1923, é considerado o início de um novo período na história da gestão ambiental global, quer por ter apresentado uma abordagem bastante completa sobre os problemas ambientais, quer pela luta para criar uma instituição internacional permanente para proteção da natureza. Porém, os problemas ambientais seriam apresentados na sua forma moderna somente no final da década de 1960 na ONU. Por forma moderna entende-se um tratamento global e integrado e não fragmentado como ocorrera até então. (BARBIERI, 2011, p. 28).

Para efetividade dessa proteção do meio ambiente, iniciou-se a implementação de uma infraestrutura internacional para gestão ambiental global. Destaca-se para criação dessa infraestrutura a criação de observatórios para monitorar e avaliar o estado do meio ambiente; maior envolvimento dos bancos multilaterais e regionais de desenvolvimento (Banco mundial, Banco Interamericano de desenvolvimento, etc.) e a criação do Programa das Nações Unidas para o Meio Ambiente (PNUMA), que passaria a centralizar grande parte das ações da ONU em relação a questões ambientais. (BARBIERI, 2011, p. 29).

Os recursos globais comuns, como a atmosfera e os oceanos fora das águas territoriais, inicialmente constituem recursos de livre acesso global, disponíveis para todos. Porém, quando as nações estabelecem acordos para limitar seu uso e evitar abusos, elas estão efetivamente transformando recursos globais de livre acesso em recursos globais de propriedade comum. É isso que procuram fazer os acordos intergovernamentais sobre meio ambiente, como os comentados

\footnotetext{
${ }^{8}$ Grupo das sete nações mais industrializadas e desenvolvidas economicamente.

${ }^{9}$ Grupo formado pelos ministros de finanças e presidentes dos Bancos centrais das 19 maiores economias do mundo, mais a União Europeia.
} 
anteriormente. Como os globais comuns são bens de todas as nações, nenhuma se sentirá na obrigação de cuidar deles sozinha. (BARBIERI, 2011, p. 59).

Assim, a expressão "governance" surge a partir de reflexões conduzidas principalmente pelo Banco Mundial. A ideia é que a capacidade governativa não seria avaliada apenas pelos resultados das políticas governamentais, mas também pela forma através da qual o governo exerce o seu poder. (GONÇALVES; 2006).

A Governança surge como uma forma de solução de problemas comuns, assim verificase que ela

(...) emergiu dos entendimentos restritos no Congresso de Viena que, em 1845, redesenhou o mapa da Europa depois da derrota da França Napoleônica, seguidos de outros eventos marcantes: fixação dos princípios do direito marítimo, em 1856, em Paris; partilha imperial na África e outras disposições colonialistas, em 1884, em Berlim; imposição de reparações à Alemanha e criação de Estados na Europa, 1910, em Versalhes; e a criação da ONU, na conferência de São Francisco, em 1945. (GONÇALVES; COSTA, 2011. p.16).

Nos meios acadêmicos, Governança passou a assumir um caráter próprio e independente a partir dos anos 80, quando o Banco Mundial e o Fundo Monetário Internacional - FMI passaram a utilizar a expressão "boa Governança" como princípio para guiar o trabalho e as ações dos estados membros.

A expressão "Governança global começou a se legitimar entre cientistas e tomadores de decisões a partir do final da década de 1980, basicamente para designar atividades geradoras de instituições (regras do jogo) que garantem que um mundo formado por Estado-nação se governe sem que disponha de governo central. (VEIGA, 2013, p. 13).

Para esses organismos a "boa Governança" deveria ter oito características: 1) participação; 2) estado de direito; 3) transparência; 4) capacidade de resposta; 5) orientação ao consenso; f) equidade e inclusão; 7) efetividade e eficiência; e 8) accountability. (GONÇALVES; COSTA, 2011, p. 31). Esses critérios são elencados no relatório "Governança para o desenvolvimento humano sustentável" do PNUD de 1997, que acrescentou o item "visão estratégica".

Em 2002 o relatório sobre o Desenvolvimento Econômico também do PNUD, desenvolveu o conceito de Governança democrática que,

(...) defendia que as liberdades civis e políticas, bem como a participação, têm valor fundamental como fim ao desenvolvimento em si mesmo. Assim, na essência, Governança democrática significa, além das instituições eficientes e ambiente previsível ao desenvolvimento econômico e político para o crescimento econômico e efetivo funcionamento dos serviços públicos, liberdades fundamentais, respeito aos direitos humanos, remoção da 
discriminação de raça, gênero e grupo ético, necessidades das futuras gerações quanto a políticas de desenvolvimento. (GONÇALVES; COSTA, 2011, p. 31)

A fase atual da Governança ambiental global se caracteriza pela implementação e aprofundamento de acordos multilaterais, o que implica colocar em prática as suas disposições e recomendações pelos estados nacionais, governos locais, empresas e outros agentes.

Destaca-se, portanto, alguns exemplos de Governanças ambientais globais multilaterais:

a) Convenção sobre mudanças climáticas devido o aquecimento global e a destruição da camada de ozônio;

b) Convenção da Biodiversidade, a qual foi aprovada na CNUMAD em $1992 \mathrm{e}$ em janeiro de 2011 já contava com a adesão de 193 países, dentre eles o Brasil, tendo como finalidade a conservação da diversidade biológica, o uso sustentável dos seus componentes e a justa e equitativa distribuição dos benefícios obtidos da utilização dos recursos genéticos, incluindo o acesso apropriado a esses recursos e a apropriada transferência de tecnologia;

c) A Convenção sobre o Comércio Internacional das Espécies da Fauna e Flora Selvagens em Perigo de Extinção (CITES), criada em 1973, tendo como objetivo controlar e limitar o comércio das espécies ameaçadas de extinção listadas em três anexos. (BARBIERI, 2011, p. 31-50)

Dentro da visão de que o Meio Ambiente não pode ser tratado entre fronteiras, verificase a necessidade de discussões e regulamentações de Governanças que sejam globais, tais como as que foram acima referendadas.

\section{DISTINÇÃO DE NOMENCLATURAS: GOVERNANÇA E GOVERNO}

Para se entender na sua completude o verdadeiro significado da palavra Governança há que se trazer algumas distinções de termos que são bastante próximos, como por exemplo, a distinção de governo, Governança e governabilidade.

Governo refere-se a atividades sustentadas por uma autoridade formal e pelo poder de polícia que garante a implementação das políticas instituídas. Seria "o conjunto de pessoas que exercem o poder político e que determinam a orientação política de uma determinada sociedade. É preciso, porém acrescentar que o poder de governo, sendo habitualmente institucionalizado, está normalmente associado à noção de Estado". (GONÇALVES; COSTA, 2011, p. 42)

Já a governabilidade refere-se à dimensão estatal do exercício do poder. "Diz respeito às condições sistêmicas e institucionais sob as quais se dá o exercício do poder, tais como as características do sistema político, a forma de governo, as relações entre os Poderes, o sistema de intermediação de interesses". (GONÇALVES, 2005). Verifica-se que está ligada diretamente no 
plano do Estado e representam um conjunto de atributos essenciais ao exercício do governo, sem os quais nenhum poder será exercido.

Já a Governança não se restringe aos aspectos gerenciais e administrativos do Estado, ela existe com a articulação e a cooperação entre os atores sociais e políticos e arranjos institucionais que coordenam e regulam transações dentro e através das fronteiras do sistema econômico. (GONÇALVES, 2005). Pode, então, ser exercida por partidos políticos, organizações não governamentais, redes sociais informais, associações, ou seja, a Governança abrange a sociedade como um todo. Nesse sentido, propõem que, “em nível transnacional, os atores não estatais, principalmente as ONG's, assumam lugar central no espaço público mundial, levando novas demandas sociais e novas instâncias de regulação sistêmica". (LORENZETTI; CARRION, 2012, p. 723).

Governança não é governo eis que este exige uma autoridade formal, com poder de polícia, trata-se ela de um fenômeno mais amplo que governo eis que abrange as instituições não governamentais bem como as instituições de caráter não governamental.

(...) governo implica em atividades apoiadas por uma autoridade formal e poderes coercitivos; já na Governança, os objetivos são atingidos não necessariamente através de uma autoridade formal que os impõem a seus membros, mas através de metas comuns e compartilhadas por todos que fazem parte do sistema. A Governança é, portanto, mais abrangente do que o governo e por isso seus objetivos e as formas de atingi-los acabam por ser mais duradouros. (ARAÚJO, 2011).

Alcindo Gonçalves (GONÇALVES, 2005) conceitua Governança como o “(...) meio e processo capaz de produzir resultados eficazes, sem necessariamente a utilização expressa da coerção. Mas a Governança não exclui a dimensão estatal: ao contrário, acaba por envolvê-la".

O relatório elaborado pela Comissão sobre Governança Global definiu Governança como "a totalidade das diversas maneiras pelas quais os indivíduos e as instituições, públicas e privadas, administram seus problemas comuns. É um processo contínuo pelo qual é possível acomodar interesses conflitantes ou diferentes e realizar ações cooperativas". (COMISSÃO SOBRE GOVERNANÇA GLOBAL, 1996, p. 02)

Assim, a Governança deve ser vista como um sistema democrático de leis e instituições sociais e o seu progresso depende de regulação, estabelecida por algum mecanismo de consenso democrático, traduzidas em instrumentos normativos capazes de assegurar a concórdia, a paz e o progresso. 
A Governança deixa de ser um atributo de algum governo para ser, de modo cada vez mais profundo, instrumento do incremento da coesão de entidades e organizações nacionais, regionais e globais.

O Estado continua tendo uma vital importância, pois os "imperativos da constituição de um sistema de Governança mundial não devem se sobrepor às prerrogativas do Estado, destacando ainda os riscos que isso implica para consolidação do processo democrático, em particular, para os países periféricos”. (LORENZETTI; CARRION, 2012, p.723).

El concepto de gobernanza en un contexto de globalización se ha ido desarrollando en la últimas tres décadas y ha cobrado relevancia desde 1190 convirtiéndose en un concepto clave en el debate político. Está relacionado con el ámbito de la toma de decisiones y con el arte de manejar las sociedades y organizaciones, influido en gran medida con el ascendo de la nueva gestión pública y el cambio de paradigma en la administración pública. (MONTIEL, 2010, p.302).

Destaca-se que Governança não é um conceito jurídico estando mais relacionada com a Ciência Política e com as Relações internacionais. Porém, considerando ser o Direito uma ciência social aplicada, interessa compreender e verificar a aplicabilidade do conceito à sua teoria prática. (GONÇALVES, 2005).

No direito interno a Governança surge como a busca de alternativas fora do plano estrito do Estado, mas é evidente que no nível doméstico a importância e relevância dos temas e ações estatais é muito mais presente. Enquanto isso, o Direito Internacional tem muito mais pontos em comum com a Governança. Como já mencionado acima, o processo de globalização tem levado à redefinição do conceito de soberania, com a emergência crescente de ONG's e empresas multi e transnacionais, significando a crescente passagem para o plano da Governança global. (GONÇALVES, 2005).

Novos problemas de dimensões transfronteiriças vão reforçar a tendência para Governança, como a poluição ambiental, a migração internacional e mesmo a globalização dos mercados e a internacionalização das corporações. Todo esse movimento resultou na limitação da competência, mandato e autoridade dos Estados nacionais. (GONÇALVES; COSTA, 2011, p. 35). Acredita-se que no futuro haverá mais e mais Governança e cada vez menos governo.

\section{A JUSTIÇA AMBIENTAL E A GOVERNANÇA AMBIENTAL GLOBAL}

Para a doutrina clássica ambiental tem-se cada vez mais trabalhado conceitos como o da Justiça Ambiental a partir da observação da disparidade nas relações ambientais entre pessoas de 
regiões distintas ou capacidades econômicas díspares. A ideia de Justiça Ambiental surgiria, então, como a ideia de justiça na distribuição do ambiente entre as pessoas.

Conforme leciona Carvalho (2014, p. 776), a Justiça Ambiental, pela referida autora sinônimo de justiça social, “[...] baseia-se na noção de que a dimensão dos recursos naturais e a desestabilização dos ecossistemas podem atingir de modo desigual e injusto, determinadas pessoas ou grupos de indivíduos." Por tais fundamentos, sua razão de existir é de constituição de uma nova expectativa que integre lutas e movimento sociais e ambientais além dos conflitos de distribuição ecológica dos recursos naturais.

Destaca Acselrad (2002, p. 4) que a problemática da discussão acerca da Justiça Ambiental se funda primordialmente na argumentação de que nem os defensores da modernização ecológica, nem os teóricos da Sociedade de Risco tiveram êxito em incorporar a diversidade social na construção do risco, tampouco a presença de uma lógica política que orientasse a distribuição desigual dos danos ambientais, tendo os movimentos por Justiça Ambiental surgido neste contexto.

Carvalho (2014, p. 760) ainda reitera que lógica é a articulação entre a degradação ambiental e a injustiça social, contudo a modernização ecológica e "[...] a sociedade de risco não vinculam a diversidade social na construção do risco e a política para orientar a distribuição desigual dos danos ambientais."

Pelos ensinamentos de Acselrad (2002, p. 760), o movimento de Justiça Ambiental teria seu germe inicial nos Estados Unidos nos anos 80 a partir de uma articulação criativa entre lutas de caráter social, territorial, ambiental e de direitos civis.

Como dito no início deste artigo, também nesse período surgem nos meios acadêmicos as discussões sobre Governança, a partir de atitudes do Banco Mundial e do Fundo Monetário internacional (FMI), que passam a estipular requisitos para o alcance da "boa Governança". Dentro desses critérios de "boa Governança" está a necessidade de "equidade e inclusão", justamente o que busca a Justiça Ambiental.

No final dos anos 60 houve a redefinição do conjunto de embates contra as condições inadequadas de saneamento, de contaminação química de locais de moradia e trabalho e disposição indevida de lixo tóxico e perigoso, acionando-se a noção de equidade geográfica. (ACSELRAD, 2002, p. 760) 
Em sequência, nos anos 70, “[...] sindicatos preocupados com saúde ocupacional, grupos ambientalistas e organizações de minorias étnicas articularam-se para elaborar em suas pautas respectivas o que entendiam por 'questões ambientais urbanas'." (ACSELRAD, 2002, p. 06). Vários estudos já apontavam uma distribuição espacialmente desigual da poluição segundo a raça das populações a ela mais expostas.

O movimento foi se afirmando a partir da experiência concreta da luta desenvolvida em Afton, condado de Warren, na Carolina do Norte, em 1982. "A partir de lutas de base contra iniquidades ambientais a nível local, similares à de Afton, o movimento elevou a 'Justiça Ambiental' à condição de questão central na luta pelos direitos civis." (ACSELRAD, 2002, p. 06). Quase que simultaneamente o movimento induziu a incorporação da desigualdade ambiental na agenda do movimento ambientalista tradicional.

Seguindo, a partir de 1987, diversas organizações começaram a discutir mais intensamente as ligações entre raça, pobreza e poluição, e pesquisadores iniciaram estudos sobre as ligações dos problemas ambientais e a desigualdade social, procurando, inclusive, elaborar instrumentos de uma "Avaliação de Equidade Ambiental" que viesse a incorporar variáveis sociais nos estudos tradicionais de avaliação de impacto. (ACSELRAD, 2002, p. 08).

Porém as reais mudanças se apresentaram a partir de 1990, quando as implicações dos estudos começaram a apresentar resultados a nível do Estado, quando a Environmental Protection Agency, do governo americano, criou um grupo de trabalho com o intuito de estudar o risco ambiental em comunidades de baixa renda. (ACSELRAD, 2002, p. 08).

A seguir, em 1991, foram aprovados na I Cúpula Nacional de Lideranças Ambientalistas de Povos de Cor, os “17 Princípios da Justiça Ambiental”, “[...] estabelecendo uma agenda nacional para redesenhar a política ambiental dos EUA de modo a incorporar a pauta das 'minorias', comunidades ameríndias, latinas, afroamericanas e asiaticoamericanas, tentando mudar o eixo de gravidade da atividade ambientalista nos EUA.” (ACSELRAD, 2002, p. 08).

Foi a partir deste momento que o movimento da Justiça Ambiental consolidou-se como uma rede multicultural e multirracial, em um primeiro momento num contexto nacional americano, e posteriormente a nível internacional.

Ademais, o tema também foi foco de evento internacional ocorrido em Niterói, no Rio de Janeiro em 2001, o Colóquio Internacional sobre Justiça Ambiental, Trabalho e Cidadania, 
evento que se consolidou na Declaração de Princípios da Rede Brasileira de Justiça Ambiental, definindo-a a partir de um conjunto de princípios e práticas:

a - asseguram que nenhum grupo social, seja ele étnico, racial ou de classe, suporte uma parcela desproporcional das conseqüências ambientais negativas de operações econômicas, de decisões políticas e de programas federais, estaduais, locais, assim como da ausência ou omissão de tais políticas;

$\mathrm{b}$ - asseguram acesso justo e eqüitativo, direto e indireto, aos recursos ambientais do país;

c - asseguram amplo acesso às informações relevantes sobre o uso dos recursos ambientais e a destinação de rejeitos e localização de fontes de riscos ambientais, bem como processos democráticos e participativos na definição de políticas, planos, programas e projetos que lhes dizem respeito;

d - favorecem a constituição de sujeitos coletivos de direitos, movimentos sociais e organizações populares para serem protagonistas na construção de modelos alternativos de desenvolvimento, que assegurem a democratização do acesso aos recursos ambientais e a sustentabilidade do seu uso. (BRASIL, s/a)

Foi nessa época também, em 2002, que o PNUD apresentou o conceito de "Governança democrática" no relatório sobre o desenvolvimento econômico, no qual destaca-se que além das instituições eficientes e ambiente previsível ao desenvolvimento econômico e político para o crescimento econômico, é necessário o efetivo funcionamento dos serviços públicos, liberdades fundamentais, respeito aos direitos humanos, remoção das discriminações de raça, gênero e grupo ético, justamente o objetivo que se quer alcançar com a Justiça Ambiental.

Interessante é o destaque de que essa ideia de Justiça Ambiental, ou justiça social, apesar de constituírem quase que um neologismo, tendo em vista que sua aparição se deu em meados dos anos 90, conforme relatado acima, pode-se dizer que possui raízes de sentidos muito mais profundas. O romano Cícero, em sua obra "Dos deveres" (CÍCERO, 2002, p. 35-37), já pressentia, ao prover uma escrita de compaixão para com seu filho, que a honestidade, na característica de dever humano, possui quatro elementos: 1) a sabedoria e a prevenção, que pertencem à descoberta da verdade (o mais natural do homem); 2) aquisição e conservação de tudo que é imprescindível à vida; 3) harmonia da sociedade humana; 4) a grandeza d'alma que mais se destaca desprezando os bens e as honras que se ambiciona para si e para os outros.

Especialmente quanto ao terceiro elemento, Cícero (2002, p. 37) aponta que sua solidificação se dá através da união entre os homens, dividindo-se em duas partes: 1) a justiça, que é a primeira qualidade do homem de bem e implica não fazer mal a ninguém, a menos que se tenha que rebater um insulto, bem como empregar em comum os bens de comunhão e tratar como próprios apenas os que nos pertencem; 2) a caridade, também chamada de bondade ou 
generosidade. Ou seja, a própria justiça aliada à solidariedade, que àquela época era entendida tão somente como caridade.

A partir de todo esse contexto que surge, então, a noção da Justiça Ambiental, Carvalho (2014, p. 763) destaca que ela surge " [...] a partir do momento em que a dimensão dos recursos naturais e a desestabilização dos ecossistemas podem afetar, de modo desigual e injusto, determinados grupos sociais, em certas áreas geográficas."

Segundo Vieira (2016, p. 256), o seu conceito se apresenta como uma nova concepção na abordagem da questão ambiental, sendo que visa a conjugação de fatores ambientais e de caráter técnico. Passa-se a reconhecer os saberes e os fazeres populares, bem como as suas construções culturais sobre o seu ambiente como fatores determinantes no trato jurídico dos conflitos incidentes sobre bens socioambientais. É uma verdadeira fonte de renovação do Direito Ambiental para um Direito da Sustentabilidade.

Nesse viés, a Justiça Ambiental pode ser concebida a partir da "[...] distribuição equitativa de riscos, custos e benefícios ambientais, independentemente de fatores não justificáveis racionalmente, tais como etnia, renda, posição social e poder; o igual acesso aos recursos ambientais e aos processos decisórios de caráter ambiental, traduzindo-se em sua democratização.” (VIEIRA, 2016, p.257).

Leff $(2011$, p. 365) a define como "[...] um conjunto de direitos que problematiza todo o sistema jurídico, tanto sua racionalidade formal como seus princípios axiológicos e seus instrumentos normativos".

Ainda, nos dizeres de Selene Herculano (2008, p. 02), Justiça Ambiental pode ser compreendida como

[...] o conjunto de princípios que asseguram que nenhum grupo de pessoas, sejam grupos étnicos, raciais ou de classe, suporte uma parcela desproporcional das consequiências ambientais negativas de operações econômicas, de políticas e programas federais, estaduais e locais, bem como resultantes da ausência ou omissão de tais políticas.

Complementarmente em sua dicotomia, InJustiça Ambiental poderia ser compreendida como “[...] o mecanismo pelo qual sociedades desiguais destinam a maior carga dos danos ambientais do desenvolvimento a grupos sociais de trabalhadores, populações de baixa renda, grupos raciais discriminados, populações marginalizadas e mais vulneráveis." As injustiças 
ambientais “[...] são as implicações das opressões de classe, raça e gênero.” (CARVALHO, 2014, p. 761)

Por tais considerações observa-se que o desenvolvimento do estudo da Justiça Ambiental, com o consequente fortalecimento do acesso à justiça e da Governança em matéria ambiental, pode ajudar a superar as omissões e ineficiências do Poder Público no que diz respeito ao controle de atividades degradadoras, bem como implementar e executar os programas de ação e políticas públicas ambientais. (VIEIRA, 2016)

Apenas a título didático destaca-se que em contraposição a esta ideia de Justiça Ambiental, Bosselmann (2015) apresenta a ideia de Justiça Ecológica, entendida pela "[...] justiça da distribuição do ambiente entre as pessoas e a justiça das relações entre os seres humanos e o resto do mundo natural." (BOSSELMANN, 2015, p. 108) Afirmando que a ideia de Justiça Ambiental não apresentaria a consideração real e necessária do mundo, de modo que os ditames apresentados por ela se baseiam nas concepções liberais de justiça e no discurso antropocêntrico da ética, o que não se mostrará suficiente no decorrer da história, sendo que deveria se focar em concepções ecológicas de justiça e no discurso ecocêntrico da ética.

A preocupação da ética ecológica é levar o mundo não humano para a comunidade da justiça para que não seja necessário confiar inteiramente em maiorias democráticas para a proteção ambiental. Ao fazer isso, todos têm o cuidado de observar que o reconhecimento do valor moral do mundo natural não indica equivalência moral com a humanidade. (BOSSELMANN, 2015, p. 114)

Seriam postulados dois princípios gerais de justiça ecológica: 1. Justiça ecológica significa que cada pessoa singular tem o direito de desfrutar a plenitude da sua própria forma de vida; e 2. Todas as formas de vida são mutuamente dependentes e dependentes de formas não vivas. (BOSSELMANN, 2015, p. 114)

Resumidamente, na ideia de Justiça Ecológica estariam incluídos não só os humanos, mas também os "não humanos" na comunidade da justiça. Estar-se-ia falando em equidade intrageracional, intergeracional e também entre espécies (justiça interespécies). Porém seriam necessários novos modelos de Governança, pois o sistema atual seria incapaz de fazer a justiça ecológica na forma doutrinariamente proposta.

A verdade é que independentemente da consideração da justiça como ambiental ou ecológica, ou até mesmo social, ela é um fator indissociável tanto da sustentabilidade como da solidariedade. Ela é o fruto da melhor equação de uma Sustentabilidade Solidária ou de uma 
Solidariedade Sustentável, calcando-se, também, como o objetivo central da Governança Ambiental.

Isso, pois o objetivo central de uma efetiva Governança ambiental está calcada na equidade e inclusão de todos, na garantia das liberdades fundamentais, com respeito aos direitos humanos, remoção da discriminação de raça, gênero e grupo étnico e necessidade das futuras gerações quanto a políticas de desenvolvimento, justamente o que se busca na Justiça Ambiental.

A realidade que se demonstra e que foi construída a partir do aporte teórico deste trabalho é a de que o real alcance da Justiça Ambiental depende de uma Governança que seja efetiva com a articulação e cooperação entre os atores sociais, políticos e arranjos institucionais que coordenam transações dentro e através das fronteiras do sistema econômico.

Conforme buscou-se deixar claro neste ensaio, a Justiça Ambiental depende de critérios formadores de Governança, seu âmbito de aplicação diz respeito, também, aos reconhecimento da humanidade como grupo único, dependente de correlação, sujeito à problemas comuns que precisam ser manejados.

Dentre os problemas comuns humanitários a má distribuição de fatores - positivos e negativos - ambientais é a raiz de diversos outros problemas, merecendo especial atenção, sendo este o enfoque que se procura dar através da Justiça Ambiental. Porém, o manejo de tais problemas deve seguir considerações e determinações de Governança, como trabalhado nos dois primeiros itens desse artigo, incluindo-se força, inclusive às organizações não governamentais ONG's, que são as principais fomentadoras desses discursos de Justiça Ambiental, e se apresentam cada vez mais com um papel central no espaço público mundial.

\section{CONSIDERAÇÕES FINAIS}

Várias foram as ocorrências de danos ambientais a nível global que chamaram a atenção da comunidade internacional para necessidade de uma maior reflexão quanto à necessidade da proteção do Meio Ambiente, sendo nesse viés de pensamento que se iniciaram as discussões acerca da necessidade de uma Governança que seja global e efetiva, e essencial nos processos de desenvolvimento econômico e social, integração e solução de problemas comuns.

Nesse sentido, há que se convir que o Meio Ambiente não pode ser tratado entre fronteiras, verificando-se a necessidade de discussões e regulamentações de Governanças que 
sejam globais como uma forma de solução de problemas comuns a partir do reconhecimento da humanidade como grupo único, dependente de correlação.

Cada vez mais tem-se trabalhado conceitos como o da Justiça Ambiental a partir da observação da disparidade nas relações ambientais entre pessoas de regiões distintas ou capacidades econômicas díspares, surgindo, então, como a ideia de justiça na distribuição do ambiente entre as pessoas. Sua razão de existir é de constituição de uma nova expectativa que integre lutas e movimento sociais e ambientais além dos conflitos de distribuição ecológica dos recursos naturais.

O movimento de Justiça Ambiental teria seu germe inicial nos Estados Unidos nos anos 80 a partir de uma articulação criativa entre lutas de caráter social, territorial, ambiental e de direitos civis, considera-se como uma das principais razões do seu surgimento a força dos movimentos sociais, liderados principalmente pelas organizações não governamentais - ONG's, que continuam sendo as principais fomentadoras desses discursos de Justiça Ambiental, e se apresentam cada vez mais com um papel central no espaço público mundial.

No desenrolar da história de tal movimento, foi somente a partir da década de 90 que a Justiça Ambiental consolidou-se como uma rede multicultural e multirracial, em um primeiro momento num contexto nacional americano, e posteriormente a nível internacional, focada em combater um grande problema comum comunitário: a má distribuição de fatores - positivos e negativos - ambientais, que acaba por gerar, também, diversos outros problemas comuns, problemas estes, como comentado, foco da Governança Ambiental Global, que deverá cuidar de seu manejo.

Ou seja, a realidade obtida a partir dessa construção teórica é a de que a Justiça Ambiental apresenta-se justamente como o objetivo central de uma efetiva Governança ambiental, estando calcada na equidade e inclusão de todos, na garantia das liberdades fundamentais, com respeito aos direitos humanos, remoção da discriminação de raça, gênero e grupo étnico e necessidade das futuras gerações quanto a políticas de desenvolvimento.

\section{REFERÊNCIAS BIBLIOGRÁFICAS}

ACSELRAD, Henri. Justiça Ambiental e Construção Social do Risco. In: Encontro da Associação Brasileira de Estudos Populacionais, XIII, 2002. Outro Preto - MG. Anais... 
Disponível

em:

<http://www.abep.nepo.unicamp.br/docs/anais/pdf/2002/GT_MA_ST5_Acselrad_texto.pdf>. Acesso em: 26 de jul. de 2016.

ARAÚJO, Izabela Viana. A Governança global e a atuação das redes internacionais de cidades. In. Encontro Nacional ABRI, 3, PUC Minas, 2011. Anais... Disponível em http://www.proceedings.scielo.br/scielo.php?pid=MSC0000000122011000200031\&script=sci_ar ttext. Consultado em 03 de agosto de 2016.

BARBIERI, José Carlos. Gestão ambiental empresarial. Conceitos, modelos e instrumentos. Ed. São Paulo, Saraiva, 2011.

BRASIL. Ministério do Meio Ambiente. Manifesto de Lançamento da Rede Brasileira de Justiça Ambiental. Disponível em: <http://www.mma.gov.br/destaques/item/8077>. Acesso em: 26 de jul. de 2016.

BOSSELMANN, Klaus. O princípio da sustentabilidade: transformando direito e Governança, 2015.

CARVALHO, Sônia Aparecida de. Justiça Social e Ambiental: um instrumento de consolidação à sustentabilidade. Revista Eletrônica Direito e Política. Itajaí, v. 9, n. 2, p. 755 $779,2^{\circ}$ quadrimestre de 2014.

CÍCERO. Dos deveres. São Paulo: Martin Claret, 2002.

COMISSÃO SOBRE GOVERNANÇA GLOBAL. Nossa comunidade global. O relatório da comissão sobre Governança Global. Rio de Janeiro: Editora FGV, 1996.

GONÇALVES, Alcindo. O conceito de Governança. In: Congresso Nacional do CONPEDI, XIV, Fortaleza, 2005. Anais do..., Florianópolis: Fundação Boiteux, 2006, p. 197213. 
GONÇALVES, Alcindo; COSTA, José Augusto Fontoura. Governança Global e Regimes Internacionais. São Paulo: Almedina, 2011.

GRANZIERA, Maria Luiza. Direito ambiental. Rio de Janeiro: Editora Atlas, 2009.

HERCULANO, Selene. O clamor por Justiça Ambiental e contra o racismo ambiental. InterfacEHS, Revista de Gestão Integrada em Saúde do Trabalho e Meio Ambiente, São Paulo, v. 3, n. 1, artigo 2, jan/abril de 2008.

LEFF, Enrique. Saber ambiental: sustentabilidade, racionalidade, complexidade, poder. Tradução de Lúcia Mathilde Endlich Orth. 8. ed. Petrópolis: Vozes, 2011.

LORENZETTI, Julia Vaz; CARRION, Rosinha Machado. Governança ambiental global: atores e cenários. Cadernos EBAPE BR, v. 10, n. 03, opinião 2. Rio de Janeiro, set. 2012.

MONTIEL, Luis Enrique Concepción. Governanza y democracia em América Latina en un contexto de globalización. In. MONTIEL Luis Concepción; HERNANDÉZ, Patricia Moctezuma (org). Governanza global y democracia. Mexicali, Baja California: Universidad Autônoma de Baja California, 2010.

PASOLD, Cesar Luis. Prática da Pesquisa Jurídica e metodologia da pesquisa jurídica. Florianópolis: OAB/SC Editora, 2007.

VEIGA, José Eli. A desgovernança mundial da sustentabilidade. São Paulo: Editora 34, 2013.

VIEIRA, Ricardo Stanziola. Justiça Ambiental e a Violação dos Direitos Humanos Socioambientais: desafios da sustentabilidade na era do desenvolvimentismo. In: CRUZ, Paulo Márcio; OLIVIERO, Maurizio; BRANDÃO, Paulo de Tarso. O Direito Contemporâneo e diálogos científicos UNIVALI e Perugia - Edição Comemorativa 10 anos do Convênio de Dupla Titulação entre a UNIVALI e a UNIPG. Perugia: UNIPG, 2016. 